\title{
The use of chelating agents with passive ultrasonic irrigation enhances root canal filling sealing ability.
}

\author{
Gisele Jung Franciscatto ${ }^{1,2,3}$, Giampiero Rossi-Fedele ${ }^{4}$, Manuela Favarin Santini, \\ Mariana de Carlo Bello ${ }^{6}$, Minéia Weber Blattes ${ }^{7}$ and Carlos Alexandre Souza Bier ${ }^{1}$ \\ ${ }^{1}$ Graduate Program in Dental Science, Federal University of Santa Maria, Santa Maria, \\ Rio Grande do Sul, Brazil. \\ ${ }^{2}$ Graduate Program in Dentistry, School of Health and Life Sciences, Pontifical Catholic \\ University of Rio Grande do Sul, Porto Alegre, Rio Grande do Sul, Brazil. \\ ${ }^{3}$ Medical and Dental Centre of the Military Police of Rio Grande do Sul, Porto Alegre, \\ Rio Grande do Sul, Brazil. \\ ${ }^{4}$ Adelaide Dental School, University of Adelaide, Australia. \\ ${ }^{5}$ School of Dentistry, Franciscan University, Santa Maria, Rio Grande do Sul, Brazil. \\ ${ }^{6}$ School of Dentistry, Lutheran University of Brazil. Canoas, Rio Grande do Sul, Brazil. \\ ${ }^{7}$ School of Pharmacy, Francisean University, Santa Maria, Rio Grande do Sul, Brazil.
}

Key words: ethylenediaminetetraacetic acid; citric acid; root canal irrigants; root canal obturation; ultrasonics.

\begin{abstract}
The aim of this study was to compare the influence of a final rinse with and without passive ultrasonic irrigation (PUI), using $17 \%$ ethylenediaminetetraacetic acid (EDTA) or 10\% citric acid (CA), with 2.5\% sodium hypochlorite (NaOCl) with PUI, on the sealing ability of root canal fillings. Root canal instrumentation was performed in single-rooted premolars using $\mathrm{NaOCl}$ as the irrigant. Subsequently, the roots were randomly allocated into four experimental groups $(n=23)$ : EDTA+PUI, EDTA, CA+PUI, CA and control group: NaOCl+PUI. The specimens were root-filled using gutta-percha with a resin-based sealer and inserted into a device to measure glucose leakage at 7 and 30 days. Kruskal-Wallis and MannWhitney tests were used to evaluate the differences between the solutions and with or without PUI. Friedman's ANOVA was used to compare time points $(P<0.05)$. PUI groups showed lower infiltration values (EDTA+PUI $0.74 \pm 0.77$ and CA+PUI $5.32 \pm 1.45$ ) when compared to the groups on which PUI was not performed (EDTA $7.20 \pm 2.18$ and CA 20.73 \pm 4.70$)$, this difference was significant for EDTA $(P<0.01)$ and CA $(P=0.000)$. Also, EDTA showed less glucose infiltration than CA, with or without PUI $(P<0.005)$. NaOCl+PUI showed a higher cumulative glucose infiltration (22.92 \pm 9.71$)$. A final rinse using EDTA or CA with PUI enhances the sealing of root canal fillings. EDTA showed less infiltration.
\end{abstract}

Corresponding author: Giampiero Rossi-Fedele. Adelaide Dental School. The University of Adelaide. Floor 10. Adelaide Health and Medical Sciences Building. Adelaide, South Australia, Australia. E-mail:giampiero.rossi-fedele@ adelaide.edu.au 


\section{El uso de agentes quelantes con irrigación ultrasónica pasiva mejora la capacidad de sellado de la obturación de conducto radicular.}

Invest Clin 2021; 62 (2): 132-139

Palabras clave: ácido etilendiaminotetraacético; ácido cítrico; irrigantes de canales radiculares, obturación de canales radiculares; ultrasonido.

Resumen. El objetivo de este estudio fue comparar la influencia de una irrigación final con o sin activación ultrasónica pasiva (PUI), utilizando ácido etilendiaminotetraacético (EDTA) al 17\% o ácido cítrico (CA) al 10\%, con hipoclorito de sodio (NaOCl) al 2,5\% con PUI, sobre el sellado de la obturación de conductos radiculares. Después de la instrumentación utilizando NaOCl como irrigante, premolares de raíz única se asignaron aleatoriamente a cuatro grupos experimentales $(\mathrm{n}=23)$ : EDTA+PUI, EDTA, CA+PUI, CA y grupo de control: $\mathrm{NaOCl}+\mathrm{PUI}$. Los conductos se obturaron utilizando gutapercha con un sellador a base de resina y se insertaron en un dispositivo para medir la infiltración de glucosa a los 7 y 30 días. Se utilizaron las pruebas de Kruskal-Wallis y Mann-Whitney para evaluar las diferencias entre las soluciones y con o sin PUI. Se utilizó el ANOVA de Friedman para comparar los puntos temporales $(\mathrm{P}<0,05)$. Los grupos de PUI mostraron menores valores de infiltración (EDTA+PUI 0,74 $\pm 0,77$ y CA+PUI 5,32 $\pm 1,45)$ en comparación con los grupos en los que no se realizó

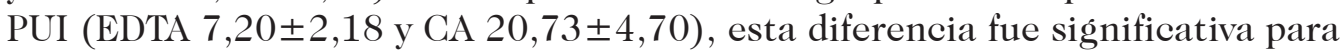
EDTA $(\mathrm{P}<0,01)$ y CA $(\mathrm{P}=0,000)$. Además, EDTA mostró menos infiltración de glucosa que CA, con o sin PUI $(\mathrm{P}<0,005)$. NaOCl+PUI mostró una mayor infiltración acumulada de glucosa $(22,92 \pm 9,71)$. Una irrigación final con EDTA o CA con PUI mejora el sellado de la obturación de conducto radicular. EDTA mostró menos infiltración.

Received: 12-11-2020 Accepted: 22-03-2021

\section{INTRODUCTION}

The endodontic literature suggests that different irrigant solutions, with or without agitation, are used globally, with the choice influenced by the diagnosis, the training of the operator and their eagerness to remove the smear layer (1-4). Despite the controversy of whether or not to remove the smear layer during root canal preparation, its reduction enhances sealing ability by promoting a closer contact between the root filling material and dentinal tubules $(5,6)$. This contact also reduces the formation of gaps between the root canal wall and the filling, which could facilitate the penetration of microorganisms from the coronal portion (6).

Therefore, one of the aims of root canal irrigation is the removal of the smear layer. Studies have shown that a sodium hypochlorite solution $(\mathrm{NaOCl})$ does not promote an effective final cleansing of the dentine walls when used alone (7). Therefore, the use of chelating agent solutions, such as $17 \%$ ethylenediaminetetraacetic acid (EDTA), complements this process by being active against the inorganic matter (7). Combining this chelator with $\mathrm{NaOCl}$ enhances root canal cleansing and improves the sealing of the root canal fill- 
ing (8). Citric acid (CA) is a chelating agent that also reacts with metals to form a soluble non-ionic chelate. Moreover, it has antibacterial activity and has a root canal cleansing ability comparable to other chelating solutions, including EDTA $(9,10)$.

Despite the use of $\mathrm{NaOCl}$ in association with chelating solutions, dentine debris and smear layer may remain on the canal walls (5), especially in irregularly shaped canals, which are difficult to access for cleaning. Thus, passive ultrasonic irrigation (PUI) is a suggested strategy, which involves activating a file inside a root canal containing an irrigating solution. When used with $\mathrm{NaOCl}$, PUI generates acoustic streaming in the solution producing a more effective cleansing (11). Using EDTA with PUI for one minute as the final irrigation method is effective in removing the smear layer and the dentinal debris in the apical third of root canals (12). Although the literature demonstrates the superiority of PUI in removing debris and cleaning isthmuses between canals $(13,14)$, there is scarce evidence regarding the effect of ultrasonic activation of chelating solutions in regards to the root fillings sealing ability $(14,15)$.

Thus, the aim of this study was to assess the effect of PUI when EDTA or CA are used as final irrigant solutions on the sealing of root canals filled with gutta-percha and $\mathrm{AH}$ Plus sealer. The tested null hypothesis was that PUI and these chelating solutions do not influence the sealing ability of root canal fillings.

\section{MATERIALS AND METHODS}

The study was approved by the Institutional Health Sciences Research Ethics Board ( $\mathrm{n}^{\circ}$ 0234.0.243.000-11) and was carried out in accordance with the Helsinki Declaration of 1975 , as revised in 2000.

\section{Teeth selection and specimen preparation}

One hundred and fifteen human premolars with a single canal, having slight or no curvature $<10^{\circ}$ for the supplementary angle (16), were selected from the teeth bank of the university. Radiographs of each premolar were exposed from two angles to verify a single canal and an oval shape, characterised by a bucco-lingual diameter twice the mesio-distal diameter (17). Root-filled teeth or those with calcified canals or other morphologies and curvatures were excluded. The teeth were kept in distilled water until use. All procedures were performed by a specialist endodontist (GJF).

The coronal portion of the included teeth was removed with a diamond bur under refrigeration, standardising the root lengths to $12 \mathrm{~mm}$. The final working length was determined by inserting a size $15 \mathrm{~K}$-file (Dentsply Maillefer, Ballaigues, Switzerland) until the tip was observed at the apical foramen and subtracting $1 \mathrm{~mm}$ from this measure. The canals were instrumented with the ProTaper system (Dentsply Maillefer), up to the instrument F3. Each set of ProTaper instruments was used for 15 canals consecutively. Final apical instrumentation was performed with a size $35 \mathrm{~K}$-file. Irrigation was performed with $1 \mathrm{~mL}$ of $2.5 \% \mathrm{NaOCl}$ after each instrument change by using a disposable syringe and Endo Eze tips (Ultradent Products Inc., Indaiatuba, SP, Brazil) placed at $3 \mathrm{~mm}$ short of the working length.

\section{Root canal irrigation}

The teeth were randomly assigned (www.random.org) to four experimental groups $(n=23)$, according to their final irrigation protocols: EDTA; EDTA+PUI; CA; $\mathrm{CA}+\mathrm{PUI}$ and one control group $\mathrm{NaOCl}+\mathrm{PUI}$.

The irrigant solutions used in the assays were as follows: $17 \%$ EDTA (Novaderme, Santa Maria, RS, Brazil); 10\% CA (Novaderme); $2.5 \% \mathrm{NaOCl}$ (Novaderme).

Irrigant solutions were delivered using a disposable syringe and Endo Eze tips with the needled tip positioned at $3 \mathrm{~mm}$ from the working length. PUI was performed with an ultrasonic adapter and coupled to a piezoelectric unit (Sonic Laxis - Schuster, 
Santa Maria, RS, Brazil) by inserting a size $15 \mathrm{~K}$-file, at a frequency of $32.000 \mathrm{~Hz}, 1 \mathrm{~mm}$ short of the working length. Three cycles of 1-minute agitation each were carried out per sample for the PUI groups. At each cycle, the root was irrigated with $1 \mathrm{~mL}$ of the solution, thus all specimens were irrigated, in total, with $3 \mathrm{~mL}$ of the solution.

A rinse with $1 \mathrm{~mL}$ of distilled water using syringe and needle as described above was carried out, and the canals were dried using paper points (Dentsply Maillefer).

\section{Root canal obturation}

The operator filling the teeth was unaware of the irrigation protocol used previously. An epoxy resin-based sealer (AH Plus, Dentsply Maillefer) was mixed according to the manufacturer's instructions and a standardised amount was placed into the root canal with a size 35 lentulo spiral. A size 35 gutta-percha point and size FF accessory points (Dentsply Maillefer) were passively inserted in the root canals without using a spreader to the depth at which resistance was met. The excess gutta-percha was severed at the level of the coronal section, using a hot condenser.

\section{Preparation and measurement of the penetration model}

The infiltration model used in the present study was proposed by Xu et al. (18). All the roots were covered with sticky wax (Asfer Indústria Química, São Caetano do Sul, SP, Brazil) and nail varnish (Risqué, São Paulo, SP, Brazil), except for the coronal access, canal entrance, and apical foramen. The coronal third was covered with sticky wax and cyanoacrylate (Loctite, Itapevi, SP, Brazil) to enable a leak-free surface between the Eppendorf microtube (Sarstedt AG \& Co. KG, Nümbrecht, NRW, Germany) and the root. This junction was also covered with nail varnish. A hole was created at the cap of the microtube, and a $14 \mathrm{~cm}$ length with a $5 \mathrm{~mL}$ capacity pipette was inserted. This assembly was positioned into a sterile $5 \mathrm{~mL}$ glass bot- tle. This interface and the interface between the pipette and the microtube were sealed with eyanoacrylate, sticky wax, and nail varnish. The glass bottle contained $2 \mathrm{~mL}$ of a $0.2 \% \mathrm{NaN}_{3}$ solution in which the apical third of the roots were immersed.

A $1 \mathrm{~mol} / \mathrm{L}$ glucose solution $(\mathrm{pH}=7.0)$ was used as the tracer. Five $\mathrm{mL}$ of this solution containing $0.2 \% \mathrm{NaN}_{3}$ were injected into the pipette until the top of the solution was at $14 \mathrm{~cm}$ from the filling level in the root canal, creating a hydrostatic pressure of $1.5 \mathrm{kPa}\left(15 \mathrm{~cm} \mathrm{H}_{2} \mathrm{O}\right)$. The glucose solution that infiltrated through the root canal was collected in the $\mathrm{NaN}_{3}$ solution in the glass bottle. All of the specimens were kept in an incubator at $37^{\circ} \mathrm{C}$.

Using a micropipette, $20 \mu \mathrm{L}$ of the solution were drawn from the glass bottle at the $7^{\text {th }}$ and $30^{\text {th }}$ days. The same aliquot of $0.2 \% \mathrm{NaN}_{3}$ was inserted into the glass bottle to maintain a constant volume. The sample was analysed with a Glucose Kit (Glicose PAP Liquiform, Labstest Diaǵnóstica S.A, Lagoa Santa, MG, Brazil). In this test, glucose was oxidised by glucose oxidase in the presence of oxygen to yield gluconic acid and hydrogen peroxide. The hydrogen peroxide that was formed reacted with 4 -amino antipyrine and phenol, and this reaction was eatalysed by peroxidase to form a red product in which the intensity of the colour is proportional to the amount of glucose in the sample. The concentration of glucose in the samples was determined via a spectrophotometer (UV- 1100 Spectrophotometer, Pró-análise Química e Diagnóstica Ltda, Porto Alegre, $\mathrm{RS}$, Brazil) at a wavelength of $505 \mathrm{~nm}$, and recorded by a blinded evaluator.

\section{Statistical analysis}

The statistical analysis was performed using SPSS Statistics for Windows, Version 17.0. (SPSS Inc., Chicago, USA). Data are presented as $\mathrm{mg} / \mathrm{dL}$. As the data were not normally distributed, Kruskal-Wallis and Mann-Whitney tests were used to evaluate the differences among the solutions and with 
or without PUI. Friedman's ANOVA was used for comparison between the time points $\left(7^{\text {th }}\right.$ and $30^{\text {th }}$ days). The significance level was set at $P<0.05$.

\section{RESULTS}

Results are presented as mean values \pm standard deviations. Glucose infiltration (mean and SD) for 7 and 30 days are presented in Figures 1 and 2. Kruskal-Wallis results showed the groups were different at both evaluated periods $(P=0.000)$. NaOCl+PUI showed a higher cumulative glucose infil- tration on 30 days $(29.79 \pm 9.71)$. According to the Mann-Whitney test, PUI groups showed lower infiltration values on both periods ( 7 days: EDTA+PUI $0.19 \pm 0.44$ and CA+PUI $4.30 \pm 1.45 ; 30$ days: EDTA+PUI $1.28 \pm 0.77$ and CA+PUI 6.35 \pm 1.45 ) when compared to the groups on which PUI was not performed ( 7 days: EDTA 5.66 \pm 1.44 and CA $17.40 \pm 3.15 ; 30$ days: EDTA $8.74 \pm 2.18$ and CA 24.05 \pm 4.70$)$, these differences were significant for EDTA $(P<0.01)$ and CA $(P=0.000)$. Also, EDTA showed less glucose infiltration than $\mathrm{CA}$, with or without PUI $(P<0.005)$.

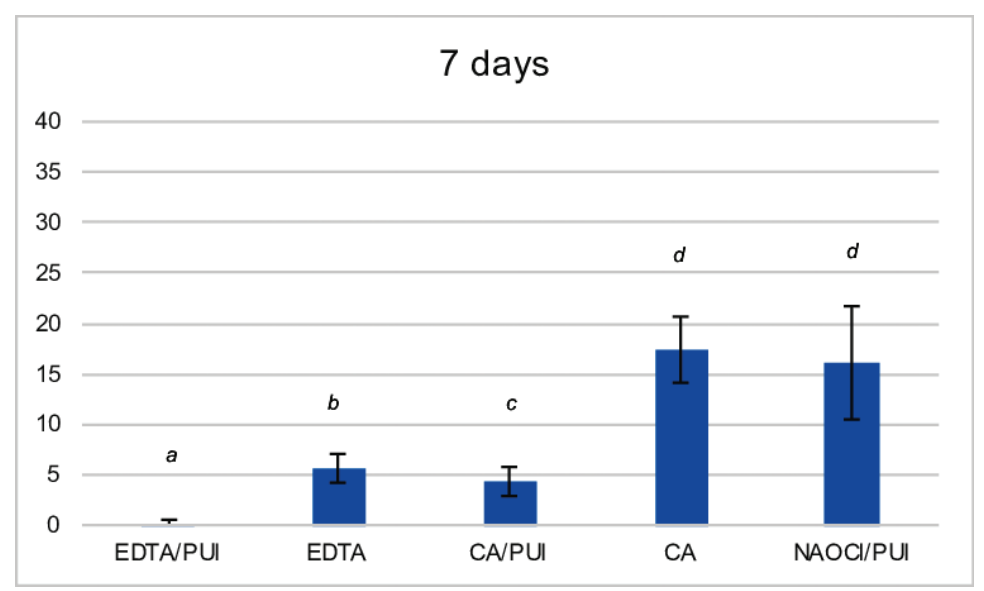

Fig. 1. Cumulative mean of glucose infiltration and SD after 7 days. Different superseript letters indicate significant difference at the Mann-Whitney test (level of significance set at <0.05). EDTA: ethylenediaminetetraacetic acid; PUI: passive ultrasonic irrigation; CA: citric acid; NaOCl: sodium hypochlorite.

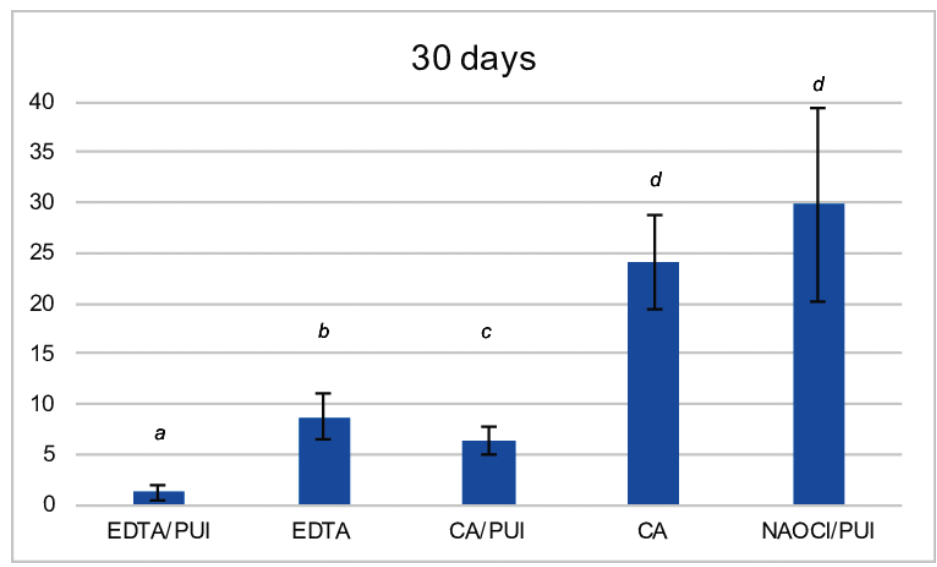

Fig. 2. Cumulative mean of ǵlucose infiltration and SD after 30 days. Different superscript letters indicate signnificant difference at Mann-Whitney test (level of significance set at <0.05). EDTA: ethylenediaminetetraacetic acid; PUI: passive ultrasonic irrigation; CA: citric acid; NaOCl: sodium hypochlorite. 
According to Friedman's ANOVA results, the glucose infiltration increased significantly from day 7 to day $30(P<0.05)$.

\section{DISCUSSION}

As a final rinse following chemo-mechanical instrumentation using $\mathrm{NaOCl}$, PUI with the chelating solutions tested promoting a better sealing when gutta-percha and a resin-based sealer were used, when compared with $\mathrm{NaOCl}$, thus rejecting the null hypothesis. This finding may be related to the synergistic relationship between the ultrasound and chelating solutions on the removal of the inorganic part of the smear layer and the positive effect of removing this layer on the sealing ability of the root canal filling $(6,11,12)$.

The influence of the smear layer on the sealing ability of the root canal filling has been studied with various methodologies. In the present study, glucose was used as the tracer due to its low molecular weight and because it is a bacterial substrate (18). Thus, it is considered of clinical relevance (18). Moreover, the glucose tracer provides a quantitative analysis of the process, also allowing the evaluation of the infiltration over time (18-21). Glucose may react with some endodontic materials, which can significantly alter experimental results (22). However, this is not the case for an epoxy resin-based sealer and gutta-percha (22), which were used for the present study. Furthermore, the glucose solution penetrates solely through the dentine-filling interface (19).

The removal of the smear layer is recommended to enhance the disinfection of the root canal system and, subsequently, to enhance the sealing of the filling material (5, $6)$. This layer is composed of necrotic debris, residual pulp, remaining dentine, and eventually, microorganisms. It results from root canal instrumentation and remains slightly adhered to the root canal walls $(23,24)$. The smear layer may act as a substrate for microorganisms, prevent the penetration of irrigant solutions and medicaments into the dentinal tubules, and interfere with the penetration and adhesion of sealers $(6,23,24)$.

Sodium hypochlorite is the most used irrigating solution in root canal treatment due to its biocidal effect and its ability to dissolve organic tissues, though it is not fully effective in smear layer removal (25). This ineffectiveness can explain the differences between the control group and the other groups in the present study and it is in agreement with a previous one (25). Chelating agents enhance smear layer removal because they can act on the inorganic particles (24). Chelation involves the reaction of the solutions with a metal to form a non-ionic soluble chelate (10). In other words, the solvent promotes the sequestration of calcium ions (inorganic particles) from the smear layer and facilitates their removal with the flushing effect of the root canal irrigants solution. This is likely enhanced by the irrigation dynamics associated with PUI.

The most widely used solution for smear layer removal is EDTA (1-4). Its maximum cleansing effect is reached after pne minute (26), which may limit secondary effects, such as decalcification and erosion of the dentinal walls (27). Kuah et al. (12) observed a better smear layer removal when EDTA was activated ultrasonically for one minute only. In the present study, to standardize with the $\mathrm{NaOCl}$ control group, this procedure was repeated twice, and the solution in question was renewed (11). When EDTA is used in association with $\mathrm{NaOCl}$ (27), or ultrasonically activated, its erosive effect is accentuated (28). Though, in our experimental set-up, this purported damage appears not to interfere with the sealing ability of the root filling.

Citric acid is a weak organic acid that also acts through chelation. In this study, CA presented with increased leakage compared to EDTA, regardless of the use of PUI. When comparing smear layer removal with $17 \%$ EDTA and MTAD, a mixture of 3\% doxycycline, 
$4.25 \%$ citric acid, and $0.5 \%$ Tween- 80 , the latter was more efficient (29). EDTA tends to be more effective than the CA for smear layer removal when there is a longer contact time (11), which may be associated with the tendency of the demineralisation capacity of CA to saturate after 60 seconds (30).

The use of PUI to potentiate the irrigation solution's effect has been previously recommended, especially in oval-shaped root canals or in canals with irregular morphology, such as isthmuses, which are harder to reach $(11,12)$. PUI agitation of $\mathrm{Na}$ OCl without the use of chelating solutions generates cleaner root canal walls, which reflects in better root canal sealing (11). In the present study, when used as a final rinse following chemo-mechanical instrumentation with $\mathrm{NaOCl}$, the use of PUI with chelating solutions was more effective than $\mathrm{NaOCl}$ alone agitated, suggesting a possible synergism between ultrasonic activation and chelating solutions. Limitations of the study included that the root canal morphology of the samples was assessed using twodimensional rather than three-dimensional imaging. This is important as the anatomy of the root canal system is considered a common confounding factor in leakage studies (31). Similarly, the root filling was carried out using a matching gutta-percha point and no condensation, and our results may not be translatable to other obturation materials and/or techniques.

Based on the findings of this study, it can be concluded that a final rinse that includes EDTA or CA, agitated with PUI, is associated with enhanced sealing ability for gutta-percha and sealer when compared with the use of the same chelators in the absence of agitation or the use of $\mathrm{NaOCl}$ with PUI. EDTA performed better than CA. These results indicate that during non-surgical root canal treatment, PUI with chelating solutions helps to promote a better sealing for root canal fillings.

\section{REFERENCES}

1. de Gregorio C, Arias A, Navarrete N, Cisneros R, Cohenca N. Differences in disinfection protocols for root canal treatment between general dentist and endodontists. J Am Dent Assoc 2015;146:536-543.

2. Savani GM, Sabbah W, Sedgley CM, Whitten B. Current trends in endodontic treatment by general dental practitioners: report of a United States national survey. J Endod 2014;40:618-624.

3. Dutner J, Mines P, Anderson A. Irrigation trends among American Association of Endodontists members: a Web-based survey. J Endod 2012;38:37-40.

4. Willerhausen I, Wolf TG, Schmidtmann I, Berger C, Ehlers V, Willerhausen B, Briseño B. Survey of root canal irrigating solutions used in dental practices within Germany. Int Endod J 2015;48:654-660.

5. Economides N, Liolios E, Kolokuris I. Long-term evaluation of the influence of smear layer removal on the sealing ability of different sealers. J Endod 1999;25:123125.

6. Shahravan A, Haghdoost A-A, Alireza A, Hessam R, Fahimeh S. Effect of smear layer on sealing ability of canal obturation: a systematic review and meta-analysis. J Endod 2007;33:96-105.

7. Goldman M, Goldman LB, Cavaleri R, Bogis J, Lin PS. The efficacy of several endodontic irrigating solutions: a scanning electron microscopic study: Part 2. J Endod 1982;8:487-492.

8. Vivacqua-Gomes $N$, Ferraz CCR, Gomes BPFA, Zaia AA, Teixeira FB, Souza-Filho FJ. Influence of irrigants on the coronal microleakage of laterally condensed gutta-percha root fillings. Int Endod J 2002;35:791-795.

9. Yamaguchi M, Yoshida K, Suzuki R, Nakamura H. Root canal irrigation with citric acid solution. J Endod 1996;22:27-29.

10. Kaushai R, Bansai R, Malhan S. A comparative evaluation of smear layer removal by using ethylenediamine tetraacetic acid, citic acid, and maleic acid as root canal irrigants: an in vitro scanning electron microscopic study. J Conserv Dent 2020;23:71-78. 
11. van der Sluis LWM, Shemesh H, Wu MK, Wesselink PR. An evaluation of the influence of passive ultrasonic irrigation on the seal of root canal fillings. Int Endod $\mathrm{J}$ 2007;40:356-361.

12. Kuah H-G, Lui J-N, Tseng PSK, Chen N-N. The effect of EDTA with and without ultrasonics on removal of the smear layer. J Endod 2009;35:393-396.

13. van der Sluis LWM, Versluis M, Wu M-K, Wesselink PR. Passive ultrasonic irrigation of the root canal: a review of the literature. Int Endod J 2007;40:415-426.

14. Burleson A, Nusstein J, Reader A, Beck M. The in vivo evaluation of hand/rotary/ultrasound instrumentation in necrotic, human mandibular molars. J Endod 2007;33:782787.

15. Singh CV, Rao SA, Chandrashekar V. An in vitro comparison of penetration depth of two root canal sealers: An SEM study. J Conserv Dent 2012;15:261-264.

16. Hartmann RC, Fensterseifer M, Peters OA, Figueredo JAP, Gomes MS, Rossi-Fedele G. Methods for the measurement of root canal curvature: a systematic and critical review. Int Endo J 2019;52:169-180.

17. Wu MK, R'oris A, Barkis D, Wesselink PR. Prevalence and extent of long oval canals in the apical third. Oral Surg Oral Med Oral Pathol Oral Radiol Endod 2000;89:739-743.

18. Xu Q, Fan M, Fan B, Cheung GSP, Hu H. A new quantitative method using glucose for analysis of endodontic leakage. Oral Surg Oral Med Oral Pathol Oral Radiol Endod 2005;99:107-111.

19. Shemesh $H$, van den Bos M, Wu M-K, Wesselink PR. Glucose penetration and fluid transport through coronal root structure and filled root canals. Int Endod $\mathrm{J}$ 2007;40:866-172.

20. De-Deus G, Soares J, Leal F, Luna AS, Fidel S, Fidel RAS. Similar ǵlucose leakage pattern on smear-covered, EDTA-treated and BioPure MTAD-treated dentin. J Endod 2008;34:459-462.

21. El Sayed MA, Taleb AA, Balbahaith MS. Sealing ability of three single-cone obturation systems: an in-vitro glucose leakage system. J Conserv Dent 2013;16:489-493.
22. Shemesh H, Souza EM, Wu M-K, Wesselink PR. Glucose reactivity with filling materials as a limitation for using the glucose leakage model. Int Endod J 2008;41:869-872.

23. Torabinejad M, Handysides R, Khademi AA, Bakland LK. Clinical implications of the smear layer in endodontics: a review. Oral Surg Oral Med Oral Pathol Oral Radiol Endod 2002;94:658-666.

24. Violich DR, Chandler NP. The smear layer in endodontics - a review. Int Endod $J$ 2010;43:2-15.

25. Wu L, Mu Y, Deng $X$, Zhang $S$, Zhou D. Comparison of the effect of four decalcifying agents combined with $60^{\circ} \mathrm{C} 3 \%$ sodium hypochlorite on smear layer removal. J Endod 2012;38:381-384.

26. Calt S, Serper A. Time-dependent effects of EDTA on dentin structures. J Endod 2002;28:17-19.

27. Ghisi AC, Kopper PM, Baldasso FE, Stürmer CP, Rossi-Fedele G, Steier L, Figueiredo JA, Morgental RD, Vier-Pelisser FV. Effect of superoxidized water and sodium hypochlorite, associated or not with EDTA, on organic and inorganic component of bovine root dentin. J Endo 2015;41:925-930.

28. Hartmann $R$, Neuvald $L$, Barth $V$, de Figueiredo JAP, Dias de Oliveira S, RossiFedele G. Antimicrobial efficacy of $0.5 \%$ peracetic acid and EDTA with passive ultrasonic or manual agitation in an Enterococcus faecalis biofilm model. Aust Endod J 2019;45:57-63.

29. Lotfi M, Vosoughhosseini S, Saghiri MA, Zand V, Ranjkesh B, Ghasemi N. Effect of MTAD as a final rinse on removal of smear layer in ten-minute preparation time. J Endod 2012;38:1391-1394.

30. Arslan H, Capar ID, Saygiili G, Uysal B, Gok T, Ertas H, Topcuoglu HS. Efficacy of various irrigation protocols on the removal of triple antibiotic paste. Int Endod J 2014;47:594-599.

31. De-Deus G. Research that matters - root canal filling and leakage studies. Int Endod J 2012;45:1063-1064. 